Article

\title{
Steady Squeezing Flow of Magnetohydrodynamics Hybrid Nanofluid Flow Comprising Carbon Nanotube-Ferrous Oxide/Water with Suction/Injection Effect
}

\author{
Muhammad Sohail Khan ${ }^{1}$, Sun Mei ${ }^{1, *}$, Shabnam ${ }^{1}$, Nehad Ali Shah ${ }^{2}\left(\mathbb{D}\right.$, Jae Dong Chung ${ }^{2}\left(\mathbb{D}\right.$, Aamir Khan ${ }^{3, *(1)}$ \\ and Said Anwar Shah ${ }^{4}$
}

Citation: Khan, M.S.; Mei, S.;

Shabnam; Ali Shah, N.; Chung, J.D.;

Khan, A.; Shah, S.A. Steady

Squeezing Flow of

Magnetohydrodynamics Hybrid

Nanofluid Flow Comprising Carbon

Nanotube-Ferrous Oxide/Water with

Suction/Injection Effect.

Nanomaterials 2022, 12, 660. https:// doi.org/10.3390/nano12040660

Academic Editors: Simone Morais and Konstantinos Spyrou

Received: 23 December 2021

Accepted: 8 February 2022

Published: 16 February 2022

Publisher's Note: MDPI stays neutral with regard to jurisdictional claims in published maps and institutional affiliations.

Copyright: (C) 2022 by the authors. Licensee MDPI, Basel, Switzerland. This article is an open access article distributed under the terms and conditions of the Creative Commons Attribution (CC BY) license (https:// creativecommons.org/licenses/by/ $4.0 /)$.
1 School of Mathematical Sciences, Jiangsu University, Zhenjiang 212013, China; sohailkhan8688@gmail.com (M.S.K.); shabnam8688@gmail.com (S.)

2 Department of Mechanical Engineering, Sejong University, Seoul 05006, Korea; nehadali199@yahoo.com (N.A.S.); jdchung@sejong.ac.kr (J.D.C.)

3 Department of Mathematics and Statistics, University of Haripur, Haripur 22620, KPK, Pakistan

4 Department of Basic Sciences and Islamiat, University of Engineering and Technology Peshawar, Peshawar 25120, KPK, Pakistan; anwarshah@uetpeshawar.edu.pk

* Correspondence: sunm@ujs.edu.cn (S.M.); aamir.khan@uoh.edu.pk (A.K.)

\begin{abstract}
The main purpose of the current article is to scrutinize the flow of hybrid nanoliquid (ferrous oxide water and carbon nanotubes) $\left(\mathrm{CNTs}+\mathrm{Fe}_{3} \mathrm{O}_{4} / \mathrm{H}_{2} \mathrm{O}\right)$ in two parallel plates under variable magnetic fields with wall suction/injection. The flow is assumed to be laminar and steady. Under a changeable magnetic field, the flow of a hybrid nanofluid containing nanoparticles $\mathrm{Fe}_{3} \mathrm{O}_{4}$ and carbon nanotubes are investigated for mass and heat transmission enhancements. The governing equations of the proposed hybrid nanoliquid model are formulated through highly nonlinear partial differential equations (PDEs) including momentum equation, energy equation, and the magnetic field equation. The proposed model was further reduced to nonlinear ordinary differential equations (ODEs) through similarity transformation. A rigorous numerical scheme in MATLAB known as the parametric continuation method (PCM) has been used for the solution of the reduced form of the proposed method. The numerical outcomes obtained from the solution of the model such as velocity profile, temperature profile, and variable magnetic field are displayed quantitatively by various graphs and tables. In addition, the impact of various emerging parameters of the hybrid nanofluid flow is analyzed regarding flow properties such as variable magnetic field, velocity profile, temperature profile, and nanomaterials volume fraction. The influence of skin friction and Nusselt number are also observed for the flow properties. These types of hybrid nanofluids $\left(\mathrm{CNTs}+\mathrm{Fe}_{3} \mathrm{O}_{4} / \mathrm{H}_{2} \mathrm{O}\right)$ are frequently used in various medical applications. For the validity of the numerical scheme, the proposed model has been solved by another numerical scheme (BVP4C) in MATLAB.
\end{abstract}

Keywords: steady; hybrid nanofluid flow; variable magnetic field; parametric continuation method (PCM); BV4C Schemes

\section{Introduction}

Heat transfer through the flow of fluid on the plate surface or on the surface of a revolving disk is gaining incredible interest from researchers due to its many uses in the aeronautical sciences and engineerings including chemical processes, thermal-energyproducing systems, geothermal industry, gas turbine rotators, medical equipment, rotating machinery, and computer storage. The squeezing flow produces by the motion of the boundaries play a significant role in polymer processing, hydrodynamical machines, lubrication equipment, etc. Due to its wide range of applications in many modern technologies, it can be considered a good source of heat transmission. Researchers have also updated the squeezing flow through the introduction of new ideas known as nanofluids. Nanofluids 
are widely used in the fields of micromanufacturing, cancer treatment, power generation, microelectronics, microchannels, thermal therapy, drug delivery, and metallurgical sectors. Choi [1] was probably the first person in technology to work on nanofluid for cooling purposes. From his study, he concluded that putting some nanoparticles into the base fluids (oil, water, and blood) make the fluid more efficient for transferring thermal conductivity. Many researchers in this field have used Choi's idea while working on nanofluids. Shahid et al. [2] numerically analyzed nanofluid by gyrostatic microorganisms in the porous medium on a stretched surface. Turkyilmazoglu [3] analyzed the slip flow pattern theoretically between concentric circular pipes. Xu et al. [4] performed a numerical study of the pulse flow of GOP water nanofluids in a microchannel for heat transmission. Ganji and Dogonchi [5] scrutinized the behavior of time-dependent MHD squeezing flow of nanoliquids between two plates regarding heat transfer using the Cattaneo-Christov heat flux model and thermal radiation. Reddy and Sreedevi [6] analyzed the impact of the chemical reaction and double classification at porous stretching sheets through nanofluid with thermal radiation regarding mass and heat transport. Arrigo et al. [7] studied the behavior of multipurpose hybrid nanofluid using carbon nanotubes (CNTs). Khan et al. [8] observed the behavior of heat transmission on the plate surface using nanofluids formulated by (CNT) nanomaterial. Water and engine oil have been used as the base fluids by Rehman et al. [9] to analyze the behavior of single and multiwall carbon nanotube nanofluids. Flow characteristics with convective heat transfer via $\mathrm{Cu}-\mathrm{Ag} /$ water hybridnanofluid are investigated by Hassan et al. [10]. The numerical and analytical solution of electro-MHD hybrid nanofluid flow in the porous medium with entropy generation has been investigated by Ellahi et al. [11]. Using CNT, Raza et al. [12] studied the development of heat conduction via peristaltic flow in a porous channel in the presence of a magnetic field. Majeed et al. [13] analyzed the heat transfer behavior with dipole effect for magnetite $\left(\mathrm{Fe}_{3} \mathrm{O}_{4}\right)$ nanomaterials that are injected into the following basic fluids, namely refrigerated, water, and kerosene. Hafeez et al. [14] recently studied the flow characteristics at a revolving disk. Using Fortran Code 21, a numerical simulation of non-Newtonian liquid $/ \mathrm{Al}_{2} \mathrm{O}_{3}$ nanofluids for (0-4) nanosize particles in a two-dimensional square gap with hot and cold lid-driven movement is performed by the Richardson method [15]. Magnetohydrodynamics (MHD) plays a significant role in a fluid motion and has many applications in different technology based on fluid flow. This is the reason most researchers are interested to study the effects of magnetic fields on the motion of the fluid. Regulating the movement of fluid is a basic principle of MHD, such as for the purpose of proper cooling. This approach can also be used in many technologies that involve the improvement of the thermal conductivity and heat transfer rate. One of the leading applications of this type of study is the merging process of the metal in the furnace under the magnetic field. Brain therapy, malignant tumors, blood pressure, and arthritis are well-known uses of magnetic fields. Hsu [16] analyzed the transient Couette flow between two parallel plates regarding heat transfer in the presence of a magnetic field. Siddiqui et al. [17] studied the movement of the MHD fluid flow in order to monitor various diseases through the respiratory tract. A numerical scheme called the Keller box algorithm has been used to solve MHD flow problems at the porous media [18]. Subhani and Nadeem in [19] considered the fluid theory to study the flow of MHD time-dependent hybrid nanofluids at a porous rotating surface. The numerical study of the 3D flow of Casson nanoliquid with chemical reactions on the stretching surface has been performed by Lokesh et al. [20]. The flow properties of $\mathrm{Cu}-\mathrm{Al}_{2} \mathrm{O}_{3} /$ water hybrid nanofluid with Joule heating and MHD on the shrinking/expanding surface has been studied in [21]. The properties of hybrid nanoliquid flow in the presence of a magnetic field on the stretching surface with slip condition has been studied by Tlili et al. [22]. In the current era of technology, the use of hybrid nanoliquids has gained much attention among researchers due to their excellent thermal properties. Hybrid nanofluids increase the rate of heat transfer compared to simple nanofluids and provide better results. Experimental studies of dissolving nanomaterials with volume fraction (1-100) $\mathrm{nm}$ have been conducted to improve heat transfer rate and thermal conductivity [23]. An experimental study has been 
conducted to analyze the temperature and concentration profile of engine oil using small particles of ZnO-MWCNTs [24]. Bovand et al. [25] investigated the properties of aluminium oxide-water nanoliquid flow at a constant temperature in the gap of two long parallel plates. In his proposed model, he also analyzed the thermophoresis power produced by the temperature variation between walls and liquid. The blending of small components into conventional fluids is a popular technique used to improve the thematic properties, which lead to enhancing the drag force [26]. In addition, a recent study of some other types of nanomaterials used in hybrid nanofluids was conducted by Waini et al. [27,28]. It has also been found that 5 percent of the volume of nanomaterials in the principle fluid is more efficient for maximum heat transfer rate. It is concluded from several studies that 5 percent of the volume fraction of nanomaterials in the principle fluid is more efficient for maximum heat transfer rate. In water-based $\mathrm{Fe}_{3} \mathrm{O}_{4}$ nanoliquids, 12-15 percent volume fraction has shown a significant influence on the Nusselt number [29-33]. Yahaya et al. [34] examined heat transfer via $\mathrm{Cu}-\mathrm{Al}_{2} \mathrm{O}_{3} / \mathrm{H}_{2} \mathrm{O}$ hybrid nanofluid on the stretching plate. The ongoing work is filling the research gap in the current literature by studying the incompressible steady flow of hybrid nanoliquid between two parallel porous plates with the variable magnetic field. The problem under consideration has not been researched and is being researched for the first time. According to the author's knowledge, the current study is a novelty in the field. The authors have also considered several flow properties in the proposed flow model, such as suction/injection, stretching, and nanomaterial volume fractions, so that the effect of different emerging parameters regarding velocity profile, temperature profile, Nusselt number, and skin friction are studied.

\section{Mathematical Formulation of the Problem}

We consider hybrid nanofluids flow in the gap of two horizontal parallel plates separated by a distance of $H(t)=H \sqrt{1-\alpha t}$, where $H$ represent the gap between plates at $t=0$. For $\alpha>0$, the two plates are squeezed until they touch at $t=\frac{1}{\alpha}$ and for $\alpha<0$, the two plates are separated, as depicted in Figure 1. Furthermore, the top plate is moving toward the bottom plate with velocity $v=\frac{d h}{d t}$. Khan et al. [35] in their work used both discs are perfectly conducted. In the present problem, electrical forces are ignored as they are much smaller than magnetic forces. An applied magnetic field is used to generate the induced magnetic field $\left(b 1_{x}, 0, b 2_{z}\right)$. Single and multiwalled carbon nanotubes are blended in base fluid water to form a hybrid nanofluid $\left(\mathrm{CNT}-\mathrm{Fe}_{3} \mathrm{O}_{4} / \mathrm{H}_{2} \mathrm{O}\right)$. Cartesian coordinates system is taken at the center of the bottom plate, where the $x$-axis lies along the horizontal axis and the $z$-axis is orthogonal to the plate. The bottom and top plates are kept at a fixed temperature $T_{0}$ and $T_{H}$, respectively. The flow properties of the hybrid nanofluid $\mathrm{CNT}-\mathrm{Fe}_{3} \mathrm{O}_{4} / \mathrm{H}_{2} \mathrm{O}$ ) under consideration are not time-dependent, resulting in more influence of the variable magnetic field. This sort of influence is considered to be due to magnetic characteristics. We have formulated hybrid nanofluid by dissolving the volume fraction of CNT $\left(\Phi_{2}=0.5\right)$ into the originally formulated ferrofluid $\left(\mathrm{Fe}_{3} \mathrm{O}_{4} / \mathrm{H}_{2} \mathrm{O}\right)$. The mathematical formulation of the aforementioned hybrid nanofluids by continuity, momentum, magnetic field, and energy conservation equations are as follows [35].

Continuity equation:

$$
\frac{\partial u}{\partial x}+\frac{\partial v}{\partial x}=0
$$

The momentum equations with magnetic effect [35-37]:

$$
\begin{aligned}
& u \frac{\partial u}{\partial x}+v \frac{\partial u}{\partial y}=-\frac{1}{\rho_{h n f}} \frac{\partial P}{\partial x}+\frac{\mu_{h n f}}{\rho_{h n f}}\left(\frac{\partial^{2} u}{\partial x^{2}}+\frac{\partial^{2} u}{\partial y^{2}}\right)-\frac{b_{2} \sigma_{h n f}}{\rho_{h n f}}\left(\frac{\partial b_{1}}{\partial y}-\frac{\partial b_{2}}{\partial x}\right) \\
& u \frac{\partial v}{\partial x}+v \frac{\partial v}{\partial y}=-\frac{1}{\rho_{h n f}} \frac{\partial P}{\partial y}+\frac{\mu_{h n f}}{\rho_{h n f}}\left(\frac{\partial^{2} v}{\partial x^{2}}+\frac{\partial^{2} v}{\partial y^{2}}\right)-\frac{b_{1} \sigma_{h n f}}{\rho_{h n f}}\left(\frac{\partial b_{1}}{\partial y}-\frac{\partial b_{2}}{\partial x}\right)
\end{aligned}
$$




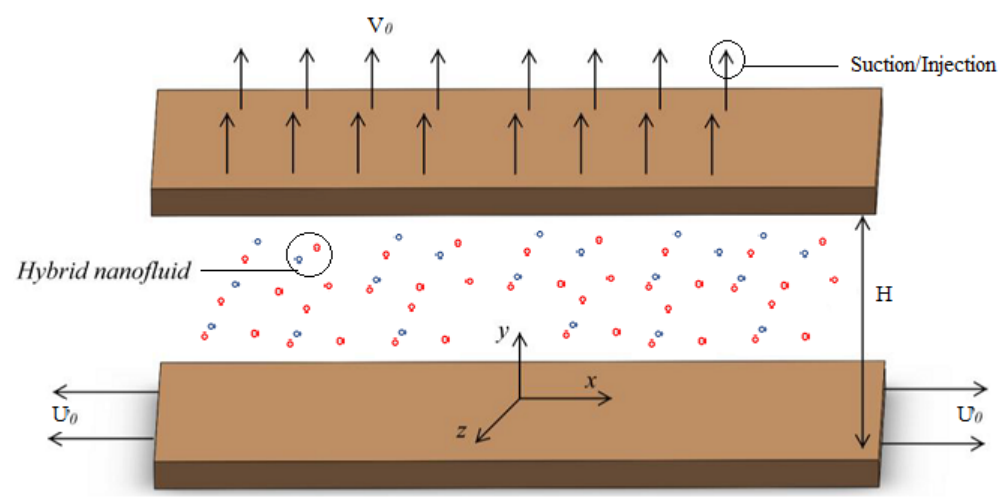

Figure 1. Geometry.

Maxwell Equations [37]:

$$
\begin{aligned}
& u \frac{\partial b_{2}}{\partial y}+b_{2} \frac{\partial u}{\partial y}-v \frac{\partial b_{1}}{\partial y}-b_{1} \frac{\partial v}{\partial y}+\frac{1}{\sigma_{h n f} \mu_{e}}\left(\frac{\partial^{2} b_{1}}{\partial x^{2}}+\frac{\partial^{2} b_{1}}{\partial y^{2}}\right)=0 \\
& v \frac{\partial b_{1}}{\partial x}+b_{1} \frac{\partial v}{\partial x}-u \frac{\partial b_{2}}{\partial x}-b_{2} \frac{\partial u}{\partial x}+\frac{1}{\sigma_{h n f} \mu_{e}}\left(\frac{\partial^{2} b_{2}}{\partial x^{2}}+\frac{\partial^{2} b_{2}}{\partial y^{2}}\right)=0
\end{aligned}
$$

The energy Equation [36]:

$$
\begin{aligned}
u \frac{\partial T}{\partial x}+v \frac{\partial T}{\partial y} & =\frac{\kappa_{h n f}}{\left(\rho C_{p}\right)_{h n f}}\left(\frac{\partial^{2} T}{\partial x^{2}}+\frac{\partial^{2} T}{\partial y^{2}}\right) \\
& +\frac{\mu_{h n f}}{\left(\rho C_{p}\right)_{h n f}}\left(4\left(\frac{\partial v}{\partial y}\right)^{2}+\left(\frac{\partial u}{\partial y}\right)^{2}+\left(\frac{\partial v}{\partial x}\right)^{2}+2 \frac{\partial u}{\partial y} \frac{\partial v}{\partial x}\right)
\end{aligned}
$$

where $b_{1}, b_{2}$ are the components of the magnetic field, $\left(\rho C_{p}\right)_{h n f}$ is the heat capacity of the hybrid nanofluid, $P$ is fluid pressure, $T$ is the temperature, $\rho_{h n f}$ is fluid density of hybrid nanofluid, $\sigma_{h n f}$ is electrical conductivity of hybrid nanofluid, and $\mu_{h n f}$ is kinematic viscosity of hybrid nanofluid.

Nanofluid are defined as [31,36]:

$$
\begin{aligned}
& v_{h n f}=\frac{\mu_{h} n f}{\rho_{h} n f}, \frac{\rho_{h n f}}{\rho_{f}}=\left(1-\Phi_{2}\right)\left(\left(1-\Phi_{1}+\frac{\Phi_{1} \rho_{M S}}{\rho_{f}}\right)+\frac{\Phi_{2} \rho_{C N T}}{\rho_{f}}\right), \\
& \frac{\kappa_{h n f}}{\kappa_{b f}}=\frac{\kappa_{C N T}+(m-1) \kappa_{b f}+\Phi_{2}\left(\kappa_{b f}-\kappa_{C N T}\right)}{\kappa_{C N T}+(m-1) \kappa_{b f}+\Phi_{2}(m-1)\left(\kappa_{b f}-\kappa_{C N T}\right)} \\
& \frac{\kappa_{b f}}{\kappa_{f}}=\left(\frac{\kappa_{M S}+(m-1) \kappa_{f}+\Phi_{1}\left(\kappa_{f}-\kappa_{M S}\right)}{\kappa_{M S}+(m-1) \kappa_{f}+\Phi_{1}(m-1)\left(\kappa_{f}-\kappa_{M S}\right)}\right) \\
& \frac{(\rho C p)_{h n f}}{\left(\rho C_{p}\right)_{f}}=\left(1-\Phi_{2}\right)\left(\left(1-\Phi_{1}+\frac{\Phi_{1}\left(\rho C_{p}\right)_{M S}}{\left(\rho C_{p}\right)_{f}}\right)+\frac{\Phi_{2}\left(\rho C_{p}\right)_{C N T}}{\left(\rho C_{p}\right)_{f}}\right), \\
& \frac{\sigma_{h n f}}{\sigma_{f}}=\left(\frac{\sigma_{C N T}+2 \sigma_{f} \sigma_{b f}-2 \Phi_{2}\left(\sigma_{b f}-\sigma_{C N T}\right)}{\sigma_{C N T}+2 \sigma_{f} \sigma_{b f}+\Phi_{2}\left(\sigma_{b f}-\sigma_{C N T}\right)}\right), \frac{\mu_{h n f}}{\mu_{f}}=\frac{1}{\left(1-\Phi_{1}\right)^{2.5}\left(1-\Phi_{2}\right)^{2.5}}, \\
& \frac{\sigma_{b f}}{\sigma_{f}}=\left(\frac{\sigma_{M S}+2 \sigma_{f}-2 \Phi_{1}\left(\sigma_{f}-\sigma_{M S}\right)}{\sigma_{M S}+2 \sigma_{f}+\Phi_{2}\left(\sigma_{f}-\sigma_{M S}\right)}\right),
\end{aligned}
$$

with $\kappa_{h n f}$ is the thermal conductivity of hybrid nanofluid, $\kappa_{b f}$ is the thermal conductivity of the $\mathrm{Fe}_{3} \mathrm{O}_{4}$-nanofuid, and $\Phi_{1}, \Phi_{2}$ are the volume fraction of CNTs. 


\section{Boundary Conditions}

The boundary conditions are chosen as [36]:

$$
\begin{aligned}
& u=0, v=V_{0}, \quad b_{1}=a x, b_{2}=-a H, T=T_{H} \quad \text { at } \quad y=h(t) \\
& u=U_{0}=a x, v=0, T=T_{0}, \quad b_{1}=b_{2}=0, \quad \text { at } y=0
\end{aligned}
$$

The following similarity transformations [36] are considered for the reducing PDEs (1)-(6) to ODEs system,

$$
\begin{aligned}
& u=a x f^{\prime}(\eta), \quad v=-a H f(\eta), \quad b_{1}=a x K^{\prime}(\eta), \\
& b_{2}=-a H K(\eta), \quad \eta=\frac{y}{H}, \quad \theta(\eta)=\frac{T-T_{H}}{T_{0}-T_{H}},
\end{aligned}
$$

Therefore, Equation (1) is satisfied and the remaining Equations (2)-(6) transform into the following form

$$
\begin{gathered}
f^{\prime \prime \prime \prime}=\frac{\rho_{h n f}}{\rho_{f}} \frac{\mu_{f}}{\mu_{h n f}}\left(S\left(f^{\prime} f^{\prime \prime}-f f^{\prime \prime \prime}\right)\right)+M^{2} S R e_{m}\left(\frac{\sigma_{h n f}}{\sigma_{f}}\right)^{2} \frac{\mu_{f}}{\mu_{h n f}}\left(f K^{2}\right) \\
-M^{2} S^{2} \operatorname{Re}_{m}^{2}\left(\frac{\sigma_{h n f}}{\sigma_{f}}\right)^{3} \frac{\mu_{f}}{\mu_{h n f}}\left(f f^{\prime} K^{2}-f^{2} K K^{\prime}\right), \\
K^{\prime \prime}=\operatorname{Re}_{m} S \frac{\sigma_{h n f}}{\sigma_{f}}\left(f^{\prime} K-f K^{\prime}\right), \\
\theta^{\prime \prime}=-\operatorname{SPr} \frac{(\rho C p)_{h n f}}{\left(\rho C_{p}\right)_{f}} \frac{\kappa_{f}}{\kappa_{h n f}}\left(\theta^{\prime} f\right)-\frac{\mu_{h n f}}{\mu_{f}} \frac{\kappa_{f}}{\kappa_{h n f}} \operatorname{Pr} E c\left(4 \delta f^{\prime 2}+f^{\prime \prime 2}\right),
\end{gathered}
$$

and the transform boundary conditions are

$$
\begin{aligned}
& f(0)=0, \quad f^{\prime}(0)=1, \quad K(0)=0, \quad \theta(0)=1, \\
& f(1)=A, \quad f^{\prime}(1)=0, \quad K(1)=1, \quad \theta(1)=0,
\end{aligned}
$$

where $\mathrm{A}$ is the suction/injection parameter, $M^{2}=\frac{H^{2} a \sigma_{f}}{\rho_{f} v_{f}}$ magnetic parameter, $S=\frac{a H^{2}}{2 v_{f}}$ squeeze number, $R e_{m}=\sigma_{f} v_{f} \mu_{e}$ Rynold's Magnetic parameter, $\operatorname{Pr}=\frac{v_{f}(\rho C p)_{f}}{\kappa_{f}} \operatorname{Prandtl}$ number, $E c=\frac{1}{(C p)_{f} T_{H}}(a x)^{2}$ Eckert number, and $\delta=\frac{H^{2}}{x^{2}}$.

Required physical parameters are the Nusselt number and skin friction coefficient, which can be defined as,

$$
C_{f}=\frac{\mu_{n f}}{\rho_{n f}\left(\frac{-\alpha l}{2 \sqrt{1-\alpha t}}\right)^{2}}\left(\frac{\partial u}{\partial z}+\frac{\partial u}{\partial r}\right)_{z=h(t)}, \quad N_{u}=-\frac{\kappa_{n} f\left(\frac{\partial T}{\partial z}\right)_{z=h(t)}}{k_{f}\left(T_{0}-T_{u}\right)}
$$

In case of Equation (16), we get

$$
\begin{aligned}
& \frac{H^{2}\left(1-\Phi_{1}\right)^{2.5}\left(1-\Phi_{2}\right)^{2.5}\left(\left(1-\Phi_{2}\right)\left(\left(1-\Phi_{1}+\frac{\Phi_{1} \rho_{M S}}{\rho_{f}}\right)+\frac{\Phi_{2} \rho_{C N T}}{\rho_{f}}\right)\right)}{r^{2}} \operatorname{ReC} C_{f}=f^{\prime \prime}(1), \\
& -\theta^{\prime}(0)=\frac{H \sqrt{1-\alpha t}}{\frac{\kappa_{C N T}+(m-1) \kappa_{b f}+\Phi_{2}\left(\kappa_{b f}-\kappa_{C N T}\right)}{\kappa_{C N T}+(m-1) \kappa_{b f}+\Phi_{2}(m-1)\left(\kappa_{b f}-\kappa_{C N T}\right)}} N_{u} .
\end{aligned}
$$

\section{Numerical Solution by PCM}

In this section, optimal choices of continuation parameters are made through the algorithm of PCM for the solution of nonlinear Equations (10)-(12) with boundary conditions in Equation (13): 
- $\quad$ First order of ODE

To transform the Equations (10)-(12) into first order of ODEs, consider the following

$$
\begin{aligned}
& f=P_{1}, \quad f^{\prime}=P_{2}, \quad f^{\prime \prime}=P_{3}, \quad f^{\prime \prime \prime}=P_{4} \\
& K=P_{5}, \quad K^{\prime}=P_{6}, \quad \theta=P_{7}, \quad \theta^{\prime}=P_{8}
\end{aligned}
$$

putting these transformations in Equations (10)-(12), which becomes

$$
\begin{gathered}
P_{4}^{\prime}=\frac{\rho_{h n f}}{\rho_{f}} \frac{\mu_{f}}{\mu_{h n f}}\left(S\left(P_{2} P_{3}-P_{1} P_{4}\right)\right)+M^{2} S R e_{m}\left(\frac{\sigma_{h n f}}{\sigma_{f}}\right)^{2} \frac{\mu_{f}}{\mu_{h n f}}\left(P_{1} P_{5}^{2}\right) \\
-M^{2} S^{2} \operatorname{Re}_{m}^{2}\left(\frac{\sigma_{h n f}}{\sigma_{f}}\right)^{3} \frac{\mu_{f}}{\mu_{h n f}}\left(P_{1} P_{2} P_{5}^{2}-P_{1}^{2} P_{5} P_{6}^{\prime}\right), \\
P_{6}^{\prime}=\operatorname{Re}_{m} S \frac{\sigma_{h n f}}{\sigma_{f}}\left(P_{2} P_{5}-P_{1} P_{6}\right), \\
P_{8}^{\prime}=-S \operatorname{Pr} \frac{(\rho C p)_{h n f}}{\left(\rho C_{p}\right)_{f}} \frac{\kappa_{f}}{\kappa_{h n f}}\left(P_{1} P_{8}\right)-\frac{\mu_{h n f}}{\mu_{f}} \frac{\kappa_{f}}{\kappa_{h n f}} \operatorname{PrEc}\left(4 \delta P_{2}^{2}+P_{3}^{2}\right),
\end{gathered}
$$

and the boundary conditions become

$$
\begin{aligned}
& P_{1}(0)=0, \quad P_{2}(0)=1, \quad P_{1}(1)=A, \quad P_{2}(1)=0, \\
& P_{5}(0)=0, \quad P_{5}(1)=1, \quad P_{7}(0)=1, \quad P_{7}(1)=0,
\end{aligned}
$$

- Introducing parameter q, we obtained ODEs in a q-parameter group,

To get ODEs in a q-parameter group, we use q-parameter in Equations (17)-(19), and, therefore,

$$
\begin{gathered}
P_{4}^{\prime}=\frac{\rho_{h n f}}{\rho_{f}} \frac{\mu_{f}}{\mu_{h n f}}\left(S\left(P_{2} P_{3}-P_{1}\left(P_{4}-1\right) q\right)\right)+M^{2} S R e_{m}\left(\frac{\sigma_{h n f}}{\sigma_{f}}\right)^{2} \frac{\mu_{f}}{\mu_{h n f}}\left(P_{1} P_{5}^{2}\right) \\
-M^{2} S^{2} R e_{m}^{2}\left(\frac{\sigma_{h n f}}{\sigma_{f}}\right)^{3} \frac{\mu_{f}}{\mu_{h n f}}\left(P_{1} P_{2} P_{5}^{2}-P_{1}^{2} P_{5} P_{6}^{\prime}\right), \\
\left.P_{6}^{\prime}=\operatorname{Re}_{m} S \frac{\sigma_{h n f}}{\sigma_{f}}\left(P_{2} P_{5}-P_{1}\left(P_{6}-1\right) q\right)\right), \\
P_{8}^{\prime}=-\operatorname{SPr} \frac{(\rho C p)_{h n f}}{\left(\rho C_{p}\right)_{f}} \frac{\kappa_{f}}{\kappa_{h n f}}\left(P_{1}\left(P_{8}-1\right) q\right)-\frac{\mu_{h n f}}{\mu_{f}} \frac{\kappa_{f}}{\kappa_{h n f}} \operatorname{PrEc}\left(4 \delta P_{2}^{2}+P_{3}^{2}\right),
\end{gathered}
$$

- Differentiation by $\mathrm{q}$ reaches at the following system w.r.t. the sensitivities to the parameter-q Differentiating the Equations (21)-(23) w.r.t. by $q$

$$
d_{1}^{\prime}=h_{1} d_{1}+e_{1}
$$

where $h_{1}$ is the coefficient matrix, $e_{1}$ is the remainder, and $d_{1}=\frac{d P_{i}}{d \tau}, 1 \leq i \leq 8$.

- $\quad$ Cauchy Problem

$$
d_{1}=y_{1}+a 1 v_{1}
$$

where $y_{1}, v_{1}$ are vector functions. By resolving the two Cauchy problems for every component, we then automatically satisfy the ODEs

$$
e_{1}+h_{1}\left(a 1 v_{1}+y_{1}\right)=\left(a 1 v_{1}+y_{1}\right)^{\prime}
$$

and leave the boundary conditions.

- Using by Numerical Solution 
An absolute scheme has been used for the resolution of the problem

$$
\begin{gathered}
\frac{v_{1}^{i+1}-v_{1}^{i}}{\triangle \eta}=h_{1} v_{1}^{i+1} \\
\frac{y^{i+1}-y^{i}}{\triangle \eta}=h_{1} y^{i+1}+e_{1}
\end{gathered}
$$

- $\quad$ Taking of the corresponding coefficients

As given boundaries are usually applied for $P_{i}$, where $1 \leq i \leq 8$, for the solution of ODEs, we required to apply $d_{2}=0$, which seems to be in matrix form as

$$
l_{1} \cdot d_{1}=0 \text { or } l_{1} \cdot\left(a 1 v_{1}+y_{1}\right)=0
$$

where $a 1=\frac{-l_{1} \cdot y_{1}}{l_{1} \cdot v_{1}}$.

\section{Error Analysis}

Error analysis is performed to study the reliability of the proposed model solution. The solution of the proposed model by PCM method is validated by BVP $4 c$ in MATLAB. In addition, to further support the validity of the solution of the proposed model, the numerical results of several parameters are tabulated (2) and (3) and displayed graphically. Table 1 illustrates the thermophysical properties of water and nanomaterial. Table 2 shows the comparison of the proposed model solution with the solution in [35]. A closed agreement has been found in the two results for different values of $S$ and $\Phi$. Further support for validating the model solution is provided in Table 3 for the numerical values of $f^{\prime \prime}(1)$ and $-\theta^{\prime}(1)$. It is evident that the model solution by two methods PCM and BVP4C are correct up to two decimal places.

Table 1. The thermophysical properties of water base fluid and hybrid nanoparticles.

\begin{tabular}{ccccc}
\hline & $\rho$ & $C_{p}$ & $\kappa$ & $\sigma$ \\
\hline $\mathrm{H}_{2} \mathrm{O}$ & 997.1 & 4179 & 0.613 & $5.5 \times 10^{-6}$ \\
$\mathrm{Fe}_{3} \mathrm{O}_{4}$ & 5200 & 670 & 6 & $9.74 \times 10^{6}$ \\
$\mathrm{SWCNT}$ & 2600 & 425 & 6600 & $10^{6}$ \\
$\mathrm{MWCNT}$ & 1600 & 796 & 3000 & $10^{7}$ \\
\hline
\end{tabular}

Table 2. Comparison of the numerical results for Nusselt number when $E c=0$.

\begin{tabular}{cccc}
\hline & $S$ & Present & Ali et al. [35] \\
\hline$\Phi=0 \%$ & 0.1 & 1.075221 & 1.078381 \\
& 0.5 & 1.401148 & 1.403658 \\
& 1.0 & 1.810361 & 1.813100 \\
$\Phi=5 \%$ & 1.5 & 2.206271 & 2.201327 \\
& 0.1 & 1.292331 & 1.298621 \\
& 0.5 & 1.613601 & 1.619052 \\
& 1.0 & 2.021148 & 2.026519 \\
& 1.5 & 2.423006 & 2.422539 \\
& 0.1 & 1.572331 & 1.573849 \\
& 0.5 & 1.883601 & 1.889474 \\
& 1.0 & 2.291148 & 2.292857 \\
\hline
\end{tabular}


Table 3. Comparison of the numerical results by two methods PCM and BVP4C for skin friction and Nusselt number, with various physical parameters.

\begin{tabular}{ccccccc}
\hline & & & PCM & BVP4C & PCM & BVP4C \\
\hline $\boldsymbol{\Phi}_{\mathbf{1}}$ & $\boldsymbol{M}$ & $\boldsymbol{S}$ & $\boldsymbol{f}^{\prime \prime}(\mathbf{1})$ & $\boldsymbol{f}^{\prime \prime}(\mathbf{1})$ & $-\boldsymbol{\theta}^{\prime}(\mathbf{1})$ & $-\boldsymbol{\theta}^{\prime}(\mathbf{1})$ \\
\hline 0.0 & 0.4 & 0.2 & -3.9734 & -3.9704 & 5.7209 & 5.7252 \\
0.3 & & & -3.9967 & -3.9909 & 5.7042 & 5.7038 \\
0.5 & & & -3.9956 & -3.9905 & 0.7386 & 0.7314 \\
& 0.6 & & -3.9388 & -3.9317 & 0.7410 & 0.7452 \\
& 0.8 & & -3.8789 & -3.8752 & 0.7434 & 0.7481 \\
& & 0.6 & -3.6286 & -3.6232 & 0.7397 & 0.7372 \\
& & 1.2 & -3.8337 & -3.8323 & 0.7082 & 0.7075 \\
\hline
\end{tabular}

\section{Results and Discussions}

In this section, we discuss the impact of various emerging parameters of the proposed model quantitatively via different graphs and tables at the velocity and magnetic profile. Hybrid nanoflow flow is observed between two long parallel plates with variable magnetic fields and phenomena of heat transfer. The impact of different key involved parameters, including Prandtl number (Pr), squeezing parameter (S), Eckert number (Ec), magnetic Reynolds number $\left(\operatorname{Re}_{m}\right)$, magnetic parameter $(\mathrm{M})$, and nanomaterials volume fraction $\left(\Phi_{1}\right.$, $\Phi_{2}$ ) are studied to analyze the behavior of mass and heat transfer. Table 1 presents the complete sketch of the thermophysical properties of various nanomaterials. The numerical outcomes of two key flow parameters such as skin friction and Nusselt number are shown in Table 2. For the validity of the numerical solution, the proposed model has been solved through two different numerical schemes (BVP4C, PCM) in MATLAB, and their numerical outcomes are displayed in Table 3 . The results obtained from the solution of the model reveals that the thermal flow rate of $\left(\mathrm{Fe}_{3} \mathrm{O}_{4}\right.$-SWCNTs-water) and $\left(\mathrm{Fe}_{3} \mathrm{O}_{4}\right.$-MWCNTs-water) rises from 0.8206 percent to 2.5233 percent and 0.9526 percent to 2.8758 percent, respectively, when the volume fraction of nanomaterial increases from 0.01 to 0.03 as depicted in Table 4 .

Table 4. The heat transfer has been calculated percent wise as for the various nanoparticles $\operatorname{Pr}=6.2$, $\mathrm{S}=1.8, \mathrm{Ec}=0.8$, using the percentage formula \%increase $=\frac{\text { With Nanoparticle }}{\text { Without Nanoparticle }} \times 100=$ Result, Result$100=\%$ enhancment.

\begin{tabular}{lcr}
\hline $\boldsymbol{\Phi}_{\mathbf{1}}, \boldsymbol{\Phi}_{\mathbf{2}}$ & $-\boldsymbol{\theta}^{\prime}(\mathbf{1})$ for $\mathrm{Fe}_{\mathbf{3}} \mathbf{O}_{4}, \mathbf{S W C N T}$ & $-\boldsymbol{\theta}^{\prime}(\mathbf{1})$ for $\mathrm{Fe}_{3} \mathbf{O}_{4}, \mathbf{M W C N T}$ \\
\hline 0.0 & 5.5324 & 5.5324 \\
0.01 & 5.5778 & 5.5851 \\
& $(0.8206 \%$ increase $)$ & $(0.9526 \%$ increase $)$ \\
0.02 & 5.6242 & 5.6381 \\
& $(1.6593 \%$ increase $)$ & $(1.9106 \%$ increase $)$ \\
0.03 & 5.6720 & 5.6915 \\
& $(2.5233 \%$ increase $)$ & $(2.8758 \%$ increase $)$ \\
\hline
\end{tabular}

In fact, as the surfaces move, fluids are squeezed in the channels, resulting in an increase in the velocity of the boundary region. Figure $2 \mathrm{~b}$ demonstrates the impact of magnetic parameter $M$ on the transverse velocity. The magnetic parameter is defined as the ratio of fluid flux to the magnetic diffusivity and it plays an important role in determining the diffusion in the magnetic field along streamlines [36]. From the figure, it has been noticed that the transverse velocity is declining due to a rise in the magnetic parameter $M$. In the same way, it has been noticed that the creation of Lorentz force due to magnetic field surging the resistance in the flow region. As the plates move forward, the flow of fluid in the channel wall is suppressed, resulting in increased velocity in the boundary area. Figure 3a illustrates the variational impact of the squeezing parameter $S$ on the axial 
velocity. The squeezing Reynolds number, $S=\frac{\beta l^{2}}{2 v_{f}}$, is the ratio of the normal velocity on the upper plate to the kinematic viscosity of the fluid. It is important to note that the large or small values of $S$ indicate slow or rapid movement of the lower plate toward the upper plate. The positive values of $S$ indicate that the bottom plate moves away from the top plate, or the distance between the plates is increased, while the negative values of $S$ indicate that the upper plate moves away from the lower plate, or the distance between two plates is decreased. The figure illustrates that the area that lies in the domain $0 \leq \eta<0.55$ represents the area near to the lower wall and the area that lies in the domain $0.55 \leq \eta \leq 1$ represents the area adjacent to the upper wall. It has been noticed that the increase in flow velocity is improving the velocity profile in the domain $\eta<0.55$ It has been observed that the fluids pass rapidly through the narrow channel when the surfaces are compressed, in this way, the velocity profile decline in the domain $\eta>0.55$, and the fluid encounter additional resistance in the wide channel. The crossflow exists in the centre of the fluid domain. It has been demonstrated in Figure $3 b$ that the velocity profile does not vary at the critical point $\eta=0.55$ with the fluctuation in the squeezing parameter and diminish for the magnetic parameter $M$. In addition, for the injection processes, the rising values of the magnetic parameter $M$ reduce the $f^{\prime}(\eta)$.

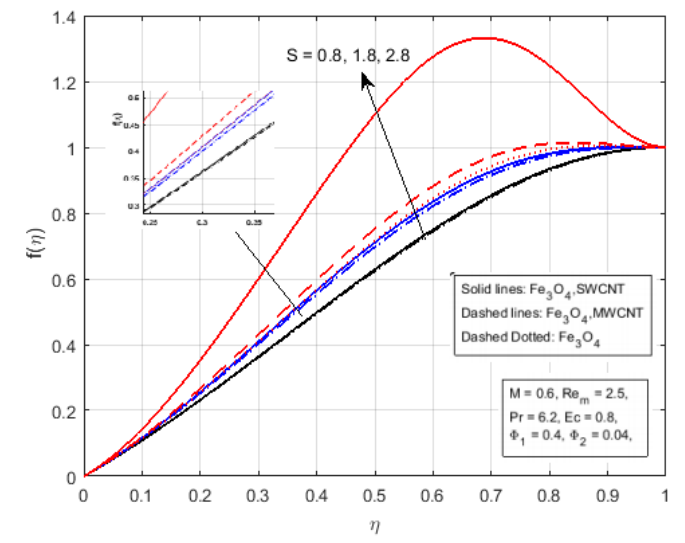

(a)

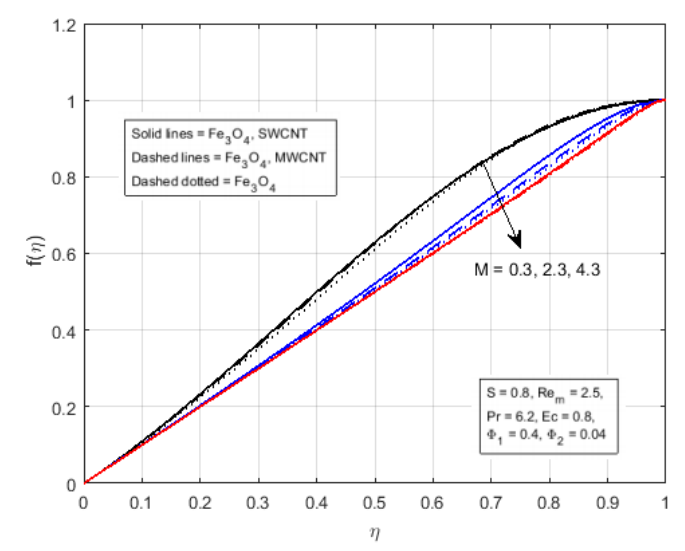

(b)

Figure 2. Effect of $f(\eta)$ for (a) $S$ and (b) $M$. 


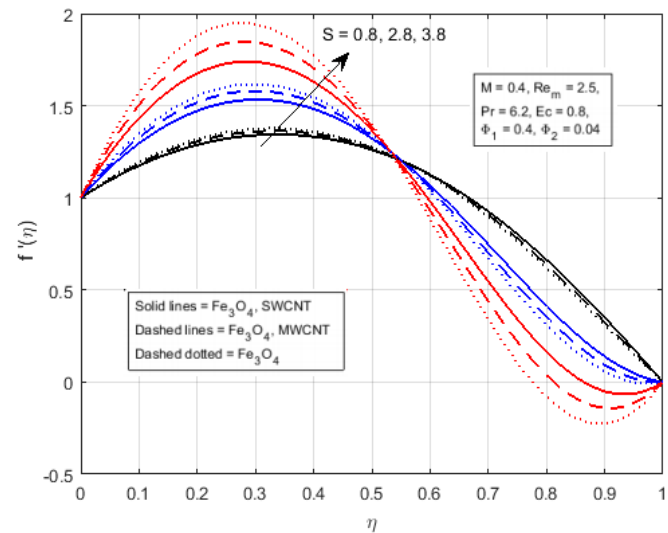

(a)

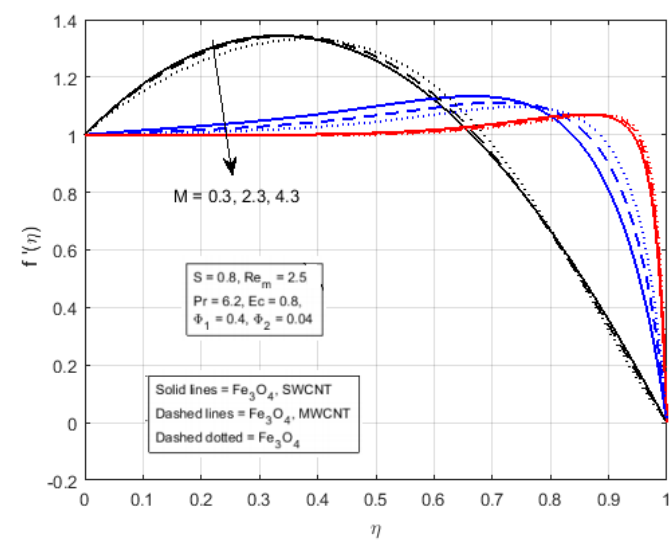

(b)

Figure 3. Effect of $f^{\prime}(\eta)$ for (a) $S$ and (b) $M$.

The impact of two nanomaterials ( CNTs and $\mathrm{Fe}_{3} \mathrm{O}_{4}$ ) with volume fraction $\left(\Phi_{1}\right.$ and $\Phi_{2}$ ) have been demonstrated in Figure 4. It reveals that the fluid flow is positively influenced by the increase in volume fraction parameters. The augmenting values of nanomaterial volume fraction $\Phi_{1}$ and $\Phi_{2}$ reduce the boundary layer thickness of the flow, thus increasing the axial velocity $f^{\prime}(\eta)$ of the fluid flow in the interval $\eta<0.56$, and decreasing in the interval $\eta>0.56$. It has been observed that the axial velocity profile is cross-flow in the centre of the boundary layer. Figure 5a demonstrates the impact of the squeezing parameter of the magnetic field profile $K(\eta)$, it reflects that the magnetic profile $K(\eta)$ is almost linear at $S=0.1$, and it becomes parabolic at a larger value of $S$, and approach to the maximum value at the middle of the channel. Figure $5 \mathrm{~b}$ illustrates the impact of $R e_{m}$ on the magnetic field profile $K(\eta)$, showing that the rising value of the magnetic Reynolds number increments the kinematic viscosity of the fluid flow. A rise in the kinematic viscosity means a fall in fluid density, which increases the magnetic field from the bottom to the upper plate, as displayed in Figure 5b. 


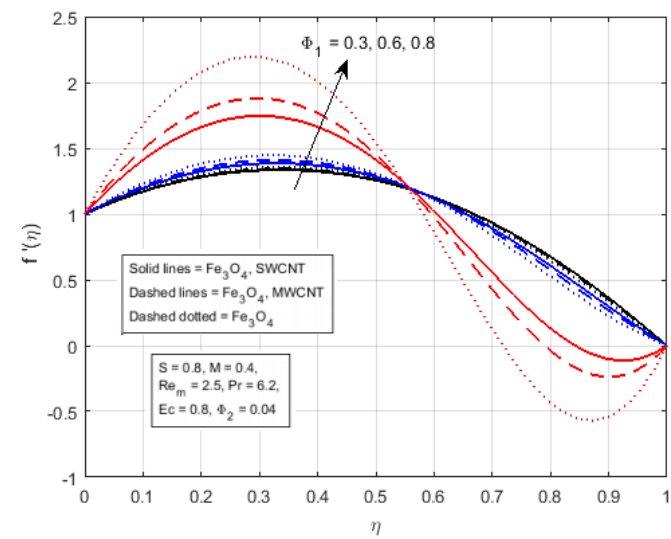

Figure 4. Effect of $f^{\prime}(\eta)$ for $\Phi_{1}$.

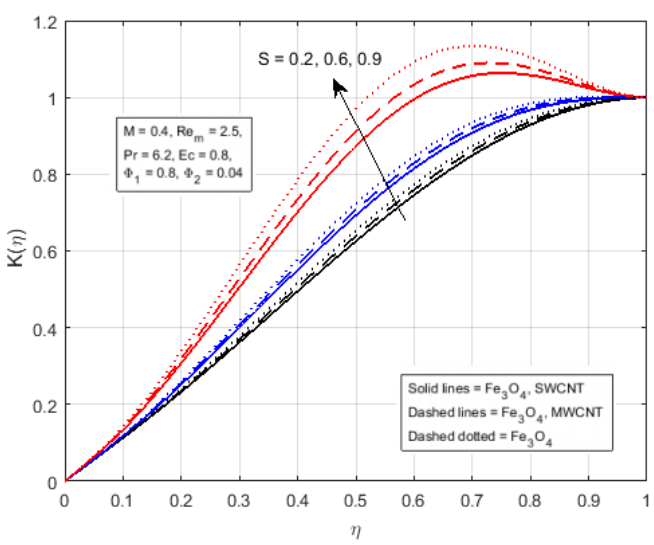

(a)

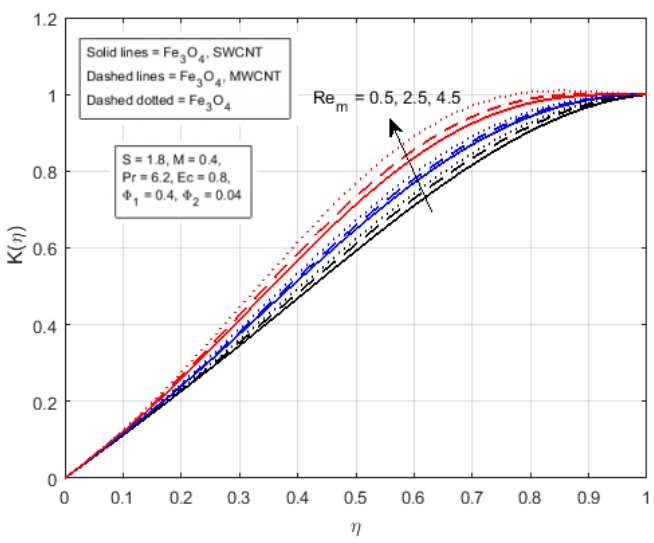

(b)

Figure 5. Effect of $K(\eta)$ for (a) $S$ and (b) $R e_{m}$.

Figure 6a is plotted to notice the impact of squeezing parameter $S$ on the temperature profile. The incrementing value of the squeezing parameter $S$ for the fluid flow produces friction, which generates a certain amount of heat, as well as increases the kinematics energy of the fluid, which also produces heat. As a result, the mean temperature of the hybrid nanofluid flow in the middle of the channel increases. A rise in Eckert number Ec lead to an increase in the thermal flow rate, as displayed in Figure $6 \mathrm{~b}$. In fact, due to the increasing values of Eckert number, fluid friction in nanomaterial is produced with greater intensity. In this physical process, kinetic energy is converted into thermal energy, which ultimately assists the increase in temperature profile, and for high values of Eckert number, 
the profile of $\theta(\eta)$ becomes parabolic and attains the maximum value at the middle of the channel. In addition, increasing the volume fraction of nanomaterials leads to an increment in the density of fluid particles. In this physical process, fluid flow is appreciated and the thermal properties of the fluid flow particles reduce. Therefore, the increasing value of $\Phi_{1}$ lead to diminishing the temperature profile, as portrayed in Figure 7, and at higher values of $\Phi_{1}$, the $\theta(\eta)$ profile becomes parabolic, and approaches to the bottom at the middle of the channel.

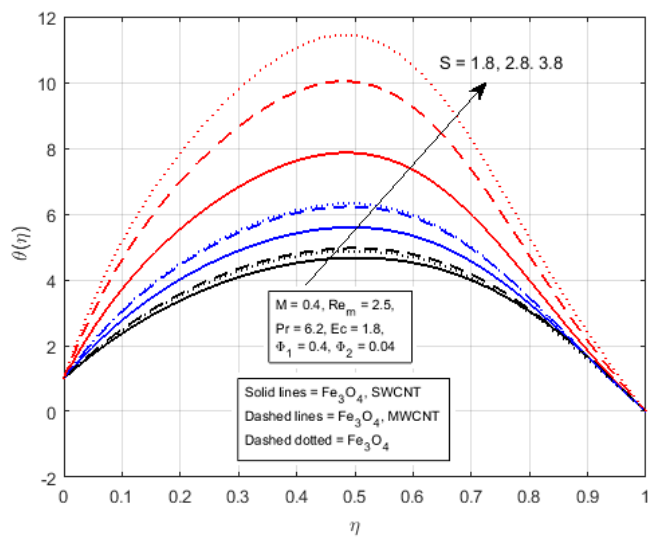

(a)

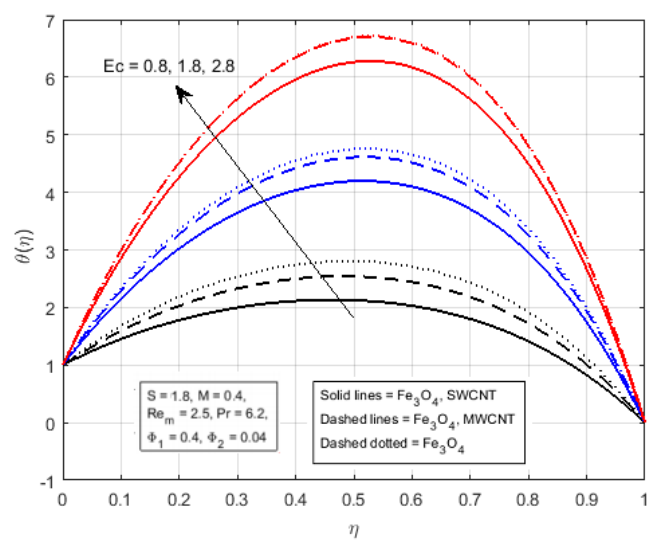

(b)

Figure 6. Effect of $\theta(\eta)$ for (a) $S$ and (b) Ec.

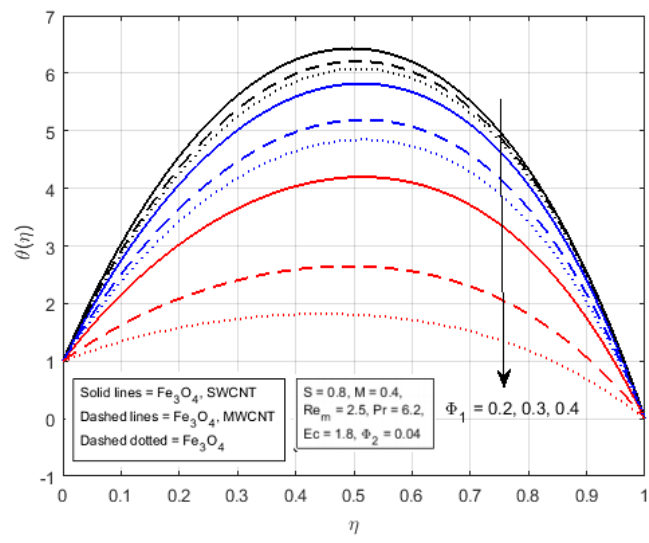

Figure 7. Effect of $\theta(\eta)$ for $\Phi_{1}$. 


\section{Concluding Remarks}

Hybrid fluid flow between two plates in the presence of variable magnetic field is considered using continuity, Navier-Stokes, Maxwell's, energy, and transport equations. The governing equations of the proposed flow model are converted into highly nonlinear systems of ODEs using similarity transformation. The numerical scheme PCM has been used for the solution of the flow model. The impacts of many involved parameters in the flow model are discussed via different graphs and tables on the velocity profile, temperature profile, and magnetic profile. The main findings of this research work are:

- As the magnetic field parameter $M$ is increasing, the transverse velocity of the hybrid nanofluid is decreasing because of the increase of electromagnetic force.

- The Lorentz force, which is produced by a magnetic field, has been observed to increase flow resistance.

- The velocity profile is reduced in the region $\eta>0.55$ because the fluid faces more resistance in the wide channel.

- The increase in the volume fraction of nanoparticles has a favorable impact on fluid flow. If $\Phi 1$ and $\Phi 2$ are increased, the thickness of the boundary layer is reduced, resulting in an increase in axial velocity $f^{\prime}(\eta)$ for $\eta<0.56$, otherwise it decreases.

- The fluid friction increases as the Eckert number rises, converting kinetic energy into thermal energy and raising the temperature profile. The Eckert number $\theta(\eta)$ becomes parabolic as the value of $\theta(\eta)$ increases, approaching the maximum value at the center.

Author Contributions: Formal analysis, J.D.C.; Funding acquisition, N.A.S.; Investigation, S.A.S.; Methodology, S.; Supervision, S.M.; Writing—original draft, M.S.K.; Writing-review \& editing, A.K. All authors have read and agreed to the published version of the manuscript.

Funding: We acknowledge the insightful comments of editorial board to enhance this work. We also acknowledge the financial support provided by the Postdoctoral research support fund of School of Mathematical Sciences, Jiangsu University, Zhenjiang, 212013, China.

Institutional Review Board Statement: Not applicable.

Informed Consent Statement: Not applicable.

Data Availability Statement: Not applicable.

Acknowledgments: We acknowledge the insightful comments of editorial board to make this work more beautiful. We also acknowledge the financial support provided by the Postdoctoral research support fund of School of Mathematical Sciences, Jiangsu University, Zhenjiang, 212013, China. This work was supported by Korea Institute of Energy Technology Evaluation and Planning (KETEP) grant funded by the Korea government (MOTIE) (No. 20192010107020, Development of hybrid adsorption chiller using unutilized heat source of low temperature).

Conflicts of Interest: The authors declare no conflict of interest.

\section{References}

1. Choi, S.U.; Eastman, J.A. Enhancing Thermal Conductivity of Fluids With Nanoparticles; CONF-951135-29 ON: DE96004174; TRN: 96:001707; Argonne National Lab.: Lemont, IL, USA, 1995. Available online: https://ANL/MSD/CP-84938 (accessed on 8 May 2021).

2. Shahid, A.; Huang, H.; Bhatti, M.M.; Zhang, L.; Ellahi, R. Numerical investigation on the swimming of gyrotactic microorganisms in nanofluids through porous medium over a stretched surface. Mathematics 2020, 8, 380. [CrossRef]

3. Turkyilmazoglu, M. Anomalous heat transfer enhancement by slip due to nanofluids in circular concentric pipes. Int. J. Heat Mass Transfer 2015, 85, 609-614. [CrossRef]

4. $\quad \mathrm{Xu}, \mathrm{C} . ; \mathrm{Xu}, \mathrm{S}$; Wei, S.; Chen, P. Experimental investigation of heat transfer for pulsating flow of GOPs-water nanofluid in a microchannel. Int. Commun. Heat Mass Transfer 2015, 110, 104403. [CrossRef]

5. Dogonchi, A.S.; Ganji, D.D. Investigation of MHD nanofluid flow and heat transfer in a stretching/shrinking convergent/divergent channel considering thermal radiation. J. Mol. Liq. 2016, 220, 592-603. [CrossRef]

6. Reddy, P.S.; Sreedevi, P. Impact of chemical reaction and double stratification on heat and mass transfer characteristics of nanofluid flow over porous stretching sheet with thermal radiation. Int. J. Ambient Energy 2020, 126, 1-11. [CrossRef] 
7. Arrigo, R.; Bellavia, S.; Gambarotti, C.; Dintcheva, N.T.; Carroccio, S. Carbon nanotubes-based nanohybrids for multifunctional nanocomposites. J. King Saud Univ. Sci. 2017, 29, 502-509. [CrossRef]

8. Khan, U.; Ahmed, N.; Asadullah, M.; Mohyud-din, S.T. Effects of viscous dissipation and slip velocity on two-dimensional and axisymmetric squeezing flow of $\mathrm{Cu}$-water and $\mathrm{Cu}-$-kerosene nanofluids. Propul. Power Res. 2015, 4, 40-49. [CrossRef]

9. Rehman, A.U.; Mehmood, R.; Nadeem, S.; Akbar, N.S.; Motsa, S.S. Effects of single and multi-walled carbon nano tubes on water and engine oil based rotating fluids with internal heating. Adv. Powder Technol. 2017, 28, 1991-2002. [CrossRef]

10. Hassan, M.; Marin, M.; Ellahi, R.; Alamri, S.Z. Exploration of convective heat transfer and flow characteristics synthesis by CuAg/water hybridnanofluids. Heat Transfer Res. 2018, 49, 1837-1848. [CrossRef]

11. Ellahi, R.; Sait, S.M.; Shehzad, N.; Ayaz, Z. A hybrid investigation on numerical and analytical solutions of electromagnetohydrodynamics flow of nanofluid through porous media with entropy generation. Int. J. Numer. Methods Heat Fluid Flow 2019, 30, 834-854. [CrossRef]

12. Raza, M.; Ellahi, R.; Sait, S.M.; Sarafraz, M.M.; Shadloo, M.S.; Waheed, I. Enhancement of heat transfer in peristaltic flow in a permeable channel under induced magnetic field using different CNTs. J. Therm. Anal. Calorim. 2020, 140, 1277-1291. [CrossRef]

13. Majeed, A.; Zeeshan, A.; Bhatti, M.M.; Ellahi, R. Heat transfer in magnetite (Fe3O4) nanoparticles suspended in conventional fluids: Refrigerant-134A (C2H2F4), kerosene $(\mathrm{C} 10 \mathrm{H} 22)$, and water $(\mathrm{H} 2 \mathrm{O})$ under the impact of dipole. Heat Transfer Res. 2020, 51, 217-232. [CrossRef]

14. Hafeez, A.; Khan, M.; Ahmed, J. Flow of Oldroyd-B fuid over a rotating disk with Cattaneo-Christov theory for heat and mass fuxes. Comput. Methods Programs Biomed. 2020, 191, 1053-1074. [CrossRef] [PubMed]

15. Nazari, S.; Ellahi, R.; Sarafraz, M.M.; Safaei, M.R.; Asgari, A.; Akbari, O.A. Numerical study on mixed convection of a nonNewtonian nanofuid with porous media in a two lid-driven square cavity. J. Term. Anal. Calorim. 2020, 140, 1121-1145. [CrossRef]

16. Hsu, J.-P.; Kao, C.-Y.; Tseng, S.; Chen, C.-J. Electrokinetic flow through an elliptical microchannel: Effects of aspect ratio and electrical boundary conditions. J. Colloid Interface Sci. 2002, 248, 176-184. [CrossRef]

17. Siddiqui, A.M.; Manzoor, N.; Maqbool, K.; Mann, A.B.; Shaheen, S. Magnetohydrodynamic fow induced by ciliary movement: An application to lower respiratory track diseases. J. Magn. Magn. Mater. 2019, 480, 164-170. [CrossRef]

18. Hafidzuddin, M.E.; Nazar, R.; Arifin, N.M. Application of the Keller-box method to magnetohydrodynamic rotating flow over a permeable shrinking surface. Embrac. Math. Divers. 2019, 130, 36-41. [CrossRef]

19. Subhani, M.; Nadeem, S. Numerical investigation into unsteady magnetohydrodynamics flow of micropolar hybrid nanofluid in porous medium. Phys. Scr. 2019, 94, 105-120. [CrossRef]

20. Lokesh, H.J.; Gireesha, B.J.; Kumar, K.G. Characterization of chemical reaction on magnetohydrodynamics flow and nonlinear radiative heat transfer of Casson nanoparticles over an exponentially sheet. J. Nanofluids 2019, 8, 1260-1266. [CrossRef]

21. Khashi'ie, N.S.; Arifin, N.M.; Nazar, R.; Hafidzuddin, E.H.; Wahi, N.; Pop, I. Magnetohydrodynamics (MHD) axisymmetric flow and heat transfer of a hybrid nanofluid past a radially permeable stretching/shrinking sheet with Joule heating. Chin. J. Phys. 2020, 64, 251-263. [CrossRef]

22. Tlili, I.; Nabwey, H.A.; Ashwinkumar, G.P.; Sandeep, N. 3-D magnetohydrodynamic AA7072-AA7075/methanol hybrid nanofluid flow above an uneven thickness surface with slip effect. Sci. Rep. 2020, 10, 13. [CrossRef] [PubMed]

23. Khan, U.; Zaib, A.; Khan, I.; Nisar, K.S. Activation energy on MHD flow of titanium alloy (Ti6Al4V) nanoparticle along with a cross flow and streamwise direction with binary chemical reaction and non-linear radiation: Dual solutions. J. Mater. Res. Technol. 2020, 9, 188-199. [CrossRef]

24. Goodarzi, M.; Toghraie, D.; Reiszadeh, M.; Afrand, M. Experimental evaluation of dynamic viscosity of ZnOMWCNTs/engine oil hybrid nanolubricant based on changes in temperature and concentration. J. Therm. Anal. Calorim. 2019, 30, 513-525. [CrossRef]

25. Bovand, M.; Rashidi, S.; Ahmadi, G.; Esfahani, J.A. Effects of trap and reflect particle boundary conditions on particle transport and convective heat transfer for duct flow-A two-way coupling of Eulerian-Lagrangian model. Appl. Therm. Eng. 2016, 108, 368-377. [CrossRef]

26. Bovand, M.; Rashidi, S.; Esfahani, J.A. Optimum interaction between magnetohydrodynamics and nanofluid for thermal and drag management. J. Thermophys. Heat Transfer 2017, 31, 218-229. [CrossRef]

27. Waini, I.; Ishak, A.; Pop, I. Hybrid nanofluid flow towards a stagnation point on a stretching/shrinking cylinder. Sci. Rep. 2020, 10, 92-96. https ://doi.org/10.1038/s4159-8-020-66126-2. [CrossRef]

28. Waini, I.; Ishak, A.; Pop, I. Hybrid nanofluid flow and heat transfer over a permeable biaxial stretching/shrinking sheet. Int. J. Numer. Meth. Heat Fluid Flow 2019, 30, 3497-3513. [CrossRef]

29. Waini, I.; Ishak, A.; Pop, I. Squeezed hybrid nanofluid flow over a permeable sensor surface. Mathematics 2020, 8, 898-905. [CrossRef]

30. Khan, M.S.; Mei, S.; Fernandez-Gamiz, U.; Noeiaghdam, S.; Shah, S.A.; Khan, A. Numerical Analysis of Unsteady Hybrid Nanofluid Flow Comprising CNTs-Ferrousoxide/Water with Variable Magnetic Field. Nanomaterials 2022, 12, 180. [CrossRef]

31. Shah, R.A.; Ullah, H.; Khan, M.S.; Khan, A. Parametric analysis of the heat transfer behavior of the nano-particle ionic-liquid flow between concentric cylinders. Adv. Mech. Eng. 2021, 13, 16878140211024009. [CrossRef]

32. Shah, R.A.; Anjum, M.N.; Khan, M.S. Analysis of unsteady squeezing flow between two porous plates with variable magnetic field. Int. J. Adv. Eng. Manag. Sci. 2017, 3, 239-756. 
33. Khan, A.; Shah, R.A.; Alam, M.K.; Rehman, S.; Shahzad, M.; Almad, S.; Khan, M.S. Flow dynamics of a time-dependent non-Newtonian and non-isothermal fluid between coaxial squeezing disks. Adv. Mech. Eng. 2021, 13, 16878140211033370. [CrossRef]

34. Yahaya, R.I.; Arifin, N.M.; Nazar, R.; Pop, I. Flow and heat transfer past a permeable stretching/shrinking sheet in Cu-Al2O3/ water hybrid nanofluid. Int. J. Numer. Meth. Heat Fluid Flow 2019, 130, 2345-2353. [CrossRef]

35. Khan, M.S.; Rehan, A.S.; Amjad, A.; Aamir, K. Parametric investigation of the NernstPlanck model and Maxwells equations for a viscous fluid between squeezing plates. Bound. Value Probl. 2019, 2019, 107. [CrossRef]

36. Chamkha, A.J.; Dogonchi, A.S.; Ganji, D.D. Magneto-hydrodynamic flow and heat transfer of a hybrid nanofluid in a rotating system among two surfaces in the presence of thermal radiation and Joule heating. AIP Adv. 2019, 9, 025103. [CrossRef]

37. Khan, M.S.; Rehan, A.S.; Aamir, K. Effect of variable magnetic field on the flow between two squeezing plates. Eur. Phys. J. Plus 2019, 134, 219. [CrossRef] 